\title{
De las Constituciones de los Estados nación al "Tratado-Constitución" de la Unión Europea
}

José Manuel Sobrino H.

El proceso de construcción europea se encuentra, tras cincuenta años de historia, en una nueva encrucijada. La Unión Europea se apresta a recibir a diez nuevos Estados miembros y sus Tratados constitutivos están siendo objeto de revisión en el marco de una Convención donde se debate su futuro. Los trabajos de esta Convención alumbrarán un texto que será sometido a una Conferencia intergubernamental de la que saldrá el instrumento jurídico destinado a regir su funcionamiento en los próximos años.

Este instrumento jurídico va a ser el resultado de un procedimiento híbrido, donde intervienen por un lado representantes de los principales sectores que participan en la construcción europea y, entre ellos, parlamentarios europeos y nacionales; y, por otro lado, los propios Estados miembros en el marco de una conferencia diplomática de corte tradicional.

Las características de tal procedimiento, el hecho de salirse de los cauces habituales de la revisión de los Tratados constitutivos de la UE, tal y como aparecen descritos en el art. 48 TUE, los intentos de dar una mayor transparencia a los debates y abrirlos a la opinión pública europea, han llevado a diversos comentaristas a hablar de un proceso cuasiconstituyente, de una futura Constitución europea, en fin, de un Tratado-Constitución.

Lo cierto es, cualquiera que sea el resultado al que se lleguen en 2004, que el proceso tradicional de revisión de los Tratados constitutivos, que en los últimos años ha sido no sólo frecuente sino también cercano en el tiempo, muestra señales evidentes de agotamiento, como reflejan elocuentemente los avatares por los que está pasando la ratificación del Tratado de Niza. En otros términos, parece que ha llegado el momento para introducir algunos cambios en la vieja doctrina comunitarista de los pequeños pasos y aventurarse en una profunda reforma de los Tratados. La cuestión ahora es la de saber si existe voluntad política y si esta voluntad puede expresarse en un entomo complejo como es el representado por la ampliación de la UE a nuevos países.La Convención, cuya creación fue decidida en el Consejo Europeo de Laeken en diciembre de 2001, viene, bajo la dirección del ex - Presidente francés Giscard d'Estaing, avanzando en su trabajo desde el pasado mes de marzo de 2002. Igualmente las instituciones europeas van haciendo llegar documentos y proyectos sobre el futuro de la Unión Europea. Otro tanto están haciendo, también, diversas organizaciones que representan a la sociedad civil europea. En la generalidad de ellos se apunta la conveniencia de renovar el método comunitario y avanzar en la integración. Este método es el resultado de un largo proceso de cincuenta años desarrollado sobre las tierras europeas y sobre el que conviene de- tenerse un momento para intentar calibrar, gracias a ello, el esfuerzo que ahora se hace en el marco de la mencionada Convención.

Una rápida visión de la historia del Continente europeo arroja como elemento identificativo la presencia de Estados nación, titulares exclusivos del ejercicio de una soberanía que se estimaba individual, abstracta y absoluta y, en cuyo marco, la organización política de los mismos giraba exclusivamente en torno a sus Constituciones nacionales. Con el tiempo, este panorama comenzó a transformarse, sobre todo desde el momento en que se crean organizaciones internacionales que pasan a detentar, también, el ejercicio de competencias soberanas. Veamos, brevemente, como se desarrollo primeramente este proceso y luego como se concretó en la actual Unión Europea.

Como es sabido, al finalizar la Segunda Guerra Mundial la situación en el Continente europeo era tal que numerosas ideas federalistas que se había ido conceptualmente construyendo en el período de entreguerras encontraron un excelente caldo de cultivo. En efecto, en aquella Europa arruinada y destruida fueron germinando una serie de movimientos, conferencias y, sobre todo, unas organizaciones internacionales, de un modelo nuevo, que inician un lento pero continuado proceso de integración de los pueblos europeos. La novedad de tales organizaciones radica en que sus Estados miembros, a través de mecanismos constitucionales internos que lo prevén, van a ceder a las mismas el ejercicio de parcelas de soberanía cada vez más amplias, dando entrada, de tal manera, a una nueva idea de soberanía, la de una soberanía relativa y divisible.

Este proceso, de corte inicialmente funcionalista, sustentado en realizaciones concretas a través de las cuales se fueran creando unas solidaridades de hecho, se inicia el 9 de mayo de 1950 con la Declaración Schuman, en la cual el entonces Ministro de Asuntos Exteriores francés anunciaba la propuesta hecha a Alemania de creación de una Comunidad Europea del Carbón y del Acero, abierta a la participación de otros países de Europa. Esta organización vio la luz el 18 de abril de 1951 y con ella aparece una nueva expresión en el lenguaje jurídico internacional, me refiero a la de supranacionalidad recogida en el art.9, párfs. 5 y 6 de su Tratado constitutivo (mención, hoy desaparecida como consecuencia de su abrogación por el art. 19 del Tratado de Fusión de 1965).

Distintos avatares internos a Europa la han ido impulsando por el camino de una progresiva integración. Este camino nos lleva a la firma en Roma el 25 de marzo de 1957 de los Tratados por los que se crean la Comunidad Económica Europea y la Comunidad Europea de la Energía Atómica, con lo que se conforman los tres elementos esenciales 
que sustentan la columna comunitaria del Ordenamiento Jurídico comunitario. Desde entonces el proceso de integración no ha cesado de avanzar, a veces más rápido otras más lentamente, hasta ir configurando una Unión Europea no ya solo económica (el Mercado interior único es una realidad el 1 de enero de 1993), sino también política (merced al Tratado de Maastricht de 7 de febrero de 1992), así como social (gracias al Tratado de Amsterdam de 2 de octubre de 1997) y, en fin, monetaria (plasmado en la moneda única, el euro, el 1 de enero de 1999).

La Unión Europea es la denominación con la que se conoce la fase actual de este proceso de integración europea que acabamos, brevemente, de esbozar. Está construida, tal y como se desprende del Tratado de Amsterdam, sobre tres pilares jurídicos: uno de naturaleza comunitaria, el conformado por las tres Comunidades preexistentes (la CECA, 1951; la CE, 1957; y, la CEEA, 1957) y dos de esencia intergubernamental: la Política Exterior y de Seguridad Común y la Cooperación en materia de Justicia Penal y Policía.

Su misión fundamental es la de organizar de modo coherente y solidario las relaciones entre los Estados miembros y entre sus pueblos. Hoy en día, el número de Estados que participan en este proceso de integración económica, política y social es el de quince, puesto que a los seis Estados originarios que conformaban la Pequeña Europa (Alemania, Bélgica, Francia, Italia, Luxemburgo y Países Bajos), se le fueron añadiendo: primero, en 1973, Dinamarca, Irlanda y el Reino Unido; más tarde, en 1981, Grecia; luego, en 1986, España y Portugal; y, finalmente, en 1995, Austria, Finlandia y Suecia. Este incremento progresivo de Estados miembros sigue abierto y desde 1998 se desarrollan negociaciones oficiales para la adhesión de nuevos países europeos.

Los objetivos que persigue la Unión Europea, tal y como aparecen enunciados en el Tratado de la Unión Europea, son los de: promover el progreso económico y social y un alto nivel de empleo y conseguir un desarrollo equilibrado y sostenible, principalmente mediante la creación de un espacio sin fronteras interiores, el fortalecimiento de la cohesión económica y social y el establecimiento de una unión económica y monetaria que implicará una moneda única; afirmar su identidad en el ámbito internacional, en particular mediante la realización de una política exterior y de seguridad común que incluya la definición progresiva de una política de defensa común; reforzar la protección de los derechos e intereses de los nacionales de sus Estados miembros, mediante la creación de una ciudadanía de la Unión; mantener y desarrollar la Unión como un espacio de libertad, seguridad y justicia, en el que esté garantizada la libre circulación de personas conjuntamente con medidas adecuadas respecto al control de las fronteras exteriores, el asilo, la inmigración y la prevención y la lucha contra la delincuencia; mantener íntegramente el acervo comunitario y desarrollarlo.

Para alcanzar estos objetivos, la Unión Europea cuenta con una estructura institucional donde aparecen reflejados los diversos intereses que intervienen en la construcción europea: los intereses de los Estados miembros (el Consejo de Ministros); los de los pueblos europeos (el Parlamento Europeo); los intereses estrictamente comunitarios, frente a los intereses singulares de los Estados miembros (la Comisión Europea); los intereses de la Comunidad de De- recho (el Tribunal de Justicia y el Tribunal de Primera Instancia); la conciencia financiera (el Tribunal de Cuentas); los intereses regionales y locales (el Comité de las regiones); y, en fin, los intereses del mundo del trabajo (el Comité Económico y Social).

Dispone además de un ordenamiento jurídico propio y autónomo, el Derecho comunitario europeo que se configura como un conjunto organizado y estructurado de normas jurídicas, que posee sus propias fuentes y está dotado de órganos y procedimientos aptos para producirlas, interpretarlas y sancionar su incumplimiento. Que se caracteriza, como veremos, por su primacía con respecto a los derechos internos de los Estados miembros y por el efecto directo de toda una serie de disposiciones comunitarias.

En este sentido, las normas comunitarias no tienen como únicos destinatarios a los Estados ni como objeto exclusivo las relaciones interestatales o los comportamientos estatales, sino que además afectan a los derechos y obligaciones de los particulares y están dirigidos a éstos, quienes pueden invocarlas ante los Tribunales. Por estas razones el Derecho comunitario europeo se configura como el ejemplo más ilustrativo de un Derecho de la integración, en su doble vertiente, de construcción teórico-conceptual y de realización de avances y experiencias concretas.

El núcleo normativo de este Derecho de integración que es el Derecho comunitario cubre, aspecialmente, el mercado interior, con sus libertades fundamentales (libre circulación de mercancías, libre circulación de trabajadores, libertad de establecimiento, libre prestación de servicios y libre circulación de capitales y pagos) y su régimen en materia de competencia. Este mercado se complementa con unas políticas comunitarias en los siguientes ámbitos: económico y monetario, agrícola, de visados, de asilo e inmigración, de transportes, fiscal, de empleo, comercial, social, de educación y juventud, cultural, de consumidores y de sanidad, de redes transeuropeas, industrial, de cohesión económica y social, de investigación y desarrollo tecnológico, ambiental y de cooperación al desarrollo. Este corpus de normas se enriquece, además, con otras de naturaleza intergubernamental en los terrenos de la cooperación en el ámbito de la Política Exterior y de Seguridad Común y en el de la cooperación policial y de justicia penal.

El Derecho comunitario se ha ido convirtiendo, progresivamente, en el verdadero cemento jurídico de la construcción europea. De manera que sin su presencia y características, difícilmente se hubiera avanzado en todos los frentes en los que la integración comunitaria europea lo ha hecho hasta la fecha. En este sentido, hay que subrayar que las comunidades europeas son no sólo fruto del Derecho (los Tratados constitutivos) sino que, además, constituyen Comunidades de Derecho y la Unión Europea, fundada en ellas, comparte esta naturaleza. El Derecho comunitario constituye, pues, un factor importante de integración y un rasgo diferenciador de la misma respecto de otros modelos de organizaciones, como son las organizaciones de cooperación e, incluso, de otras que inmersas también en procesos de integración se encuentran aún en fases menos adelantadas (Mercosur o Comunidad Andina). Ello explica, además, que las relaciones que se dan en la UE entre sus sujetos (Estados miembros, instituciones y personas jurídicas y físicas) se hayan legalizado en una alta medida y se encuentren ba- 
jo el control del Tribunal de Justicia de las Comunidades Europeas a quien compete garantizar el respeto del Derecho en la interpretación y aplicación de las normas comunitarias (art. 220 TCE).

Pero, además, si el Derecho comunitario constituye un verdadero Derecho de integración, se debe, en buena medida, a que ha conseguido implantarse profundamente en la realidad jurídica de los Estados miembros y ello gracias a que es concebido, interpretado y aplicado como una norma uniforme por los ciudadanos, las administraciones y los organos jurisdiccionales de todos los Estados miembros y al hecho de que son los propios particulares quienes lo han invocado ante sus jueces nacionales, como reconoce una reiterada jurisprudencia iniciada en la STJCE de 5 de febrero de 1963 (Van Gend en Loos, 26/62, Rec. p.1), lo que en parte convierte a estos últimos en unos importantes instrumentos de control de la correcta aplicación de este Derecho.

Ello ha permito que el propio proceso de integración europeo haya, a su vez, gestado un Ordenamiento de corte constitucional autónomo (véanse, en este sentido, los pronunciamientos del TJCE: STJCE de 23 de abril de 1986 , Los Verdes, 294/83, Rec. p.1339; Dictamen C-1/91 de 14 de diciembre de 1991, EEE, Rec.p. I-6079; Dictamen 3/94 de 13 de diciembre de 1995, GATT-OMC-Acuerdo marco sobre los plátanos), donde tienen cabida principios y normas cuyos destinatarios no son únicamente los Estados y las Instituciones comunitarias, sino que, además, afectan a los derechos y obligaciones de los propios ciudadanos comunitarios y están dirigidos a éstos, quienes pueden invocarlas ante sus Tribunales. Mediante el mismo se regulan las relaciones de todos los sujetos de la Unión Europea entre sí y con su estructura institucional se fijan los objetivos comunes, se distribuyen las competencias y se establecen las reglas de juego mediante las cuales se adoptan las decisiones de obligado cumplimiento, aplicables directamente en los Estados miembros y con primacía sobre la legislación nacional. Todo ello implica, de un lado, los necesarios ajustes y previsiones en las Constituciones políticas de los Estados miembros y, de otro, supone la aparición, merced a la atribución del ejercicio de competencias soberanas a las Instituciones de la Unión Europea, de un modelo constitucional aplicable a los Tratados constitutivos de esta organización internacional. Lo que encierra un problema jurídico: un Tratado no es una Constitución, una organización internacional no es un Estado Federal. Aspectos que paso a examinar a continuación.

El proceso de integración europeo se cimienta sobre el Derecho comunitario europeo. Este Derecho de integración, propio y autónomo, se crea, aplica y desarrolla gracias a que los Estados miembros han consentido limitar, a favor de las Instituciones comunitarias y en ámbitos específicos, el ejercicio de sus derechos soberanos.

En efecto, para conseguir los objetivos mencionados y para desarrollar mediante unas normas jurídicas propias y autónomas el mercado interior único y las políticas que lo complementan, la Unión Europea tiene atribuidas una serie de funciones y de competencias. En este sentido, cabe destacar a título preliminar como la Unión Europea y las Comunidades europeas sobre las que se sustenta, no gozan de competencias ilimitadas y ello a pesar de estar destinadas a la prosecución de amplias metas y a ejercer poderes de vas- to alcance, puesto que, a diferencia de los Estados y a semejanza de las demás organizaciones internacionales, no poseen, según la expresión tradicional, más que una simple competencia de atribución.

Este principio aparece claramente enunciado en el art. 5 del Tratado CE, donde se dice que: La Comunidad actuará dentro de los límites de las competencias que le atribuye el presente Tratado y de los objetivos que éste le asigna.

Pero quién dice atribución de competencias a las Instituciones comunitarias, dice lógicamente, también, limitación correlativa de poderes soberanos de los Estados miembros. Este fenómeno, definidor de los procesos de integración, ha sido puesto de relieve por la jurisprudencia del TJCE, donde se ha subrayado como, a diferencia de los tratados internacionales ordinarios, el tratado de la CEE instituyó un ordenamiento jurídico propio, que al quedar integrado en el sistema jurídico de los Estados miembros a partir de la entrada en vigor del mismo, se ha impuesto a sus jurisdicciones; y como, al crearse una Comunidad de duración ilimitada, dotada de instituciones propias, de personalidad, de capacidad jurídica, con capacidad de representación internacional y, más concretamente, de poderes efectivos que emanan de una limitación de competencia o de una transferencia de atribuciones de los Estados a la Comunidad, estos últimos han limitado, aunque en esferas delimitadas, sus derechos soberanos y creado, de esta forma, un derecho aplicable tanto a sus nacionales como a ellos mismos (STJCE, de 15 de julio de 1964, Costa c. ENEL, Rec. 1964, p. 1159).

El buen desarrollo de este fenómeno paralelo de atribución de competencias y de desposeimiento de poderes soberanos debe descansar en dos datos ineludibles y previos: uno, que los sistemas constitucionales internos de los Estados miembros lo permitan, esto es, que las Constituciones políticas hallan preparado el terreno; $y$, dos, que dichos Estados no estén aferrados a la doctrina de la soberanía absoluta, pues si tal ocurriera, sería imposible su participación en organizaciones de integración.

Por lo que se refiere a este segundo dato, vemos como la atribución de competencias -test, vuelvo a insistir, en todo proceso de integración- descansa en una noción de soberanía alejada de la tradicional idea de una soberanía abstracta individual, inalienable y absoluta. En efecto, si por soberanía entendemos -en la clásica definición del Prof. Carrillo Salcedo- el conjunto de competencias y derechos de que cada Estado independiente es titular en sus relaciones con otros Estados, cabe suponer que todo proceso de integración parte de la idea de la divisibilidad de su ejercicio. Al respecto, podemos ver, además, como son varios los factores que, hoy en día, están erosionando la imagen casi mítica de la soberanía, por un lado la progresiva institucionalización de la comunidad internacional y el consiguiente incremento de las funciones atribuidas a las organizaciones internacionales, por otro lado, la configuración de un orden público internacional, mediante el establecimiento de normas jurídicas imperativas, con la consiguiente merma del relativismo que ha sido una característica tradicional del Derecho internacional y que se evidencia en las transformaciones relativas a los derechos humanos, los crímenes internacionales, la responsabilidad internacional del Estado, etc. Y, en fin, por otro lado, la presencia, en algunos ámbitos, de ciertos actores internacionales que concentran el poder económico y 
US BIBL

que como consecuencia del fenómeno mundializador de los mercados no reparan en fronteras, ocasionando el consiguiente debilitamiento de aquellos elementos que la doctrina estima indisociables de la noción de soberanía: esto es, el ejercicio de las competencias y funciones de Estado con exclusividad, plenitud y autonomía.

Es el ejercicio divisible de la soberanía, lo que permite a unos Estados asociarse con otros y ceder todos parcelas de la misma para su ejercicio común por unas instituciones con la finalidad de alcanzar unos intereses colectivos. Ello que no supone, ni mucho menos, el negar a la soberanía su condición de elemento esencial del sistema internacional del que aún continúa constituyendo su clave de bóveda. Ahora bien, es esta idea la que posibilita los necesarios reajustes, fusiones o ejercicios comunes de estas competencias soberanas que conlleva todo proceso de integración y, en particular, el representado por la construcción europea

Esta noción de soberanía, al facilitar la cesión del ejercicio de competencias, plantea, en cada caso concreto, la necesidad de determinar quién, Estado o Unión Europea, detenta dicho ejercicio sin que se excluyan, según los casos, ni las acciones conjuntas ni la realización por el Estado de actividades subordinadas. Este procedimiento trae como corolario que las instituciones comunitarias no van a disfrutar siempre del mismo tipo de competencias y que variarán según las acciones a desarrollar, de manera que en algunos ámbitos gozarán de competencias exclusivas, en otros estas competencias las compartirán con los Estados miembros y, en otros, no tendrán ningún tipo de competencias. Además, en el caso en que estemos ante competencias compartidas, la actuación comunitaria deberá efectuarse respetando el principio de subsidiariedad, en el sentido de que esta actuación solo tendrá lugar cuando razones de necesidad y de eficacia así lo exijan. Conformándose este principio en un elemento fundamental en los procesos de integración.

Como se ha repetido desde la doctrina, este reparto de competencias evoca, evidentemente, los modelos estatales federales. Pero las diferencias con los mismos son sustanciales, así y a diferencia de las Constituciones federales, los Tratados constitutivos de las Comunidades Europea no contienen títulos o capítulos consagrados al problema de la atribución de competencias. En efecto, esta atribución no se hace por materias sino en forma de acciones a realizar, funciones a cumplir, por lo que habrá que descender a las disposiciones concretas de estos Tratados para saber cuáles son los poderes impartidos, qué institución es la beneficiaria y en qué formas y condiciones se ejercitará dichas competencias.

El Derecho comunitario nace, pues, en virtud de atribuciones de competencias de los Estados miembros a las Comunidades, cuyas instituciones pasan a ejercer efectivamente las competencias soberanas que les han sido cedidas. En este sentido, lo que caracteriza a la UE es que sus Estados miembros han renunciado al ejercicio de competencias soberanas, y no sólo a aquellas que son relativas a concretas materias técnicas (como ocurre en la generalidad de las organizaciones internacionales) sino también, y esto es lo novedoso, respecto a funciones que corresponden al ámbito esencial de la propia existencia en tanto Estado.

Ahora bien, hay que advertir, antes que nada, que se trata de una cesión voluntaria, esto es, no nos encontramos ante una imposición. En efecto, al respecto debemos partir de la propia noción de organización internacional que, como se sabe, la califica de asociación voluntaria de Estados creada por un Tratado internacional. De ello se desprende que los Estados miembros, conocedores de las características del ordenamiento jurídico comunitario y de la organización internacional al que corresponde, deciden, libre y voluntariamente, adherirse a la Unión Europea; con ello resuelven, igualmente, obligarse por su Tratado constitutivo y por los actos normativos de sus Instituciones. A partir del momento de la adhesión los Estados miembros no podrán ya invocar sus propias Constituciones para sustraerse a las obligaciones derivadas del Tratado de adhesión. Tal obstáculo viene consagrado en una reiterada jurisprudencia del Tribunal Internacional de Justicia y en los arts. 26, 27 y 46 de los Convenios de Viena sobre derecho de los Tratados de 1969 y 1986. En efecto, todo Estado, independientemente de sus preceptos constitucionales, como sujeto internacional está obligado a respetar sus compromisos internacionales, no pudiendo invocar frente a otros Estados parte en el tratado su propia Constitución para sustraerse a las obligaciones que éste le impone.

Por otro lado, el Derecho que regula una organización en proceso de integración, como es el caso de la UE, no puede ser concebido como un Derecho estático, sino como un ordenamiento jurídico sujeto a una profunda evolución, por lo que todo intento de valoración del mismo debe tener en cuenta esta condicionante temporal. Y, así, al estar suponiendo este proceso una verdadera transferencia del ejercicio de competencias soberanas de los Estados miembros a favor de las instituciones comunes, en materias cada vez más amplias y diversas, se le ha ido otorgando al Ordenamiento Jurídico de la Unión Europea una cada vez mayor autonomía respecto de los Derechos nacionales y del Derecho internacional. Tal evolución ha añadido nuevos elementos de complejidad en el debate en torno a la naturaleza jurídica de esta organización y a las características de el Derecho que viene creando.

En relación con ello, cabe recordar que la cuestión de la naturaleza jurídica de las Comunidades Europeas y de la Unión Europea ha retenido, de siempre, la atención de la doctrina. Así, desde comienzos de los años cincuenta en que se creó la CECA, distintas respuestas han intentado resolver esta cuestión. Estos intentos se han traducido en una amplísima literatura jurídica, sin que se haya conseguido dar una respuesta completa y definitiva debido principalmente al hecho de que las Comunidades Europeas y la Unión Europea se encuentran inmersas, como señalaba, en un proceso de cambio permanente. De manera que las diferentes teorías reflejan y determinan al mismo tiempo el clima y las perspectivas políticas de la época en que fueron formuladas, éste ha sido el caso de las denominadas teorías: federalista, internacionalista, supranacionalista o funcionalista, entre otras que, a mi entender, han sido superadas por el propio proceso de construcción europea que no puede encerrarse en ninguno de estos modelos histórico-teóricos.

Lo que me parece indudable es que la Unión Europea no constituye una Federación, ni que en el horizonte se vislumbren unos Estados Unidos de Europa, por utilizar una expresión muy querida por los federalistas de entreguerras. Eso si, nos encontramos ante un modelo original de organización internacional, que se aleja de las organizaciones inter- 
nacionales clásicas o de cooperación y al que algunos han denominado Organización supranacional, si bien, yo prefiero calificarla, simplemente, de Organización de integración, o utilizando un paralelismo con la fórmula antes mencionada, unos Estados Integrados de Europa.

Sus particularidades derivan de la circunstancia de que se trata, como dijera el juez Pescatore, de una organización que es, ante todo, una organización integradora de Estados, y no, como el Estado una organización integradora de individuos. Idea que parece también inspirar la conocida sentencia del Tribunal Constitucional Alemán, de 12 de octubre de 1993, cuando afirmaba que el Tratado de Maastricht de 1992, que estaba examinando, sería el fundamento de una unión cada vez más estrecha de los pueblos de Europa, organizados en Estados, pero no de un Estado cimentado en un pueblo europeo.

Ello nos aleja, a mi juicio, de la idea de supranacionalidad entendida como sustento de un Super-Estado, esto es, en tanto que fenómeno jurídico que supone la creación de un nuevo sujeto internacional dotado de soberanía y, además, superior a los entes estatales que lo componen (que por ello deberían, en el plano internacional, perder soberanía y, consiguientemente, uno de los elementos constitutivos de la noción de Estado). Pero esto creo que no ocurre ni tiene por que ocurrir en relación con la UE, donde a lo que más se ha llegado es a la cesión no de la soberanía sino del ejercicio de competencias soberanas, en parcelas que aunque cada vez son más amplias, también están, hay que decirlo, perfectamente delimitadas en la mayor parte de los casos.

Ello nos acercaría a otra idea de supracionalidad que implicaría, en la línea recogida por Rubio Llorente, la existencia de una estructura integrada por Estados distintos que mantienen la titularidad de sus soberanía, pero dotada también de órganos propios cuyas decisiones se imponen a los Estados miembros, más precisamente, que tienen efecto directo en el territorio de los Estados y que, en caso de colisión, prevalecen sobre las normas dictadas por los Estados. Esto es, una estructura propia de una organización que se encuentra en proceso de integración. Ahora bien, es un proceso de integración singular que, además, se aleja de otros modelos similares que se desarrollan en otras partes del mundo y, en particular, en América Latina. Descritos de forma concisa esta idea y este proceso se sustentarían, a mi entender, sobre el siguiente esquema.

- La base del proceso son unos Tratados internacionales concluidos por Estados soberanos. Por medio de ellos los Estados crean unas organizaciones internacionales a las que les atribuyen competencias. El sujeto creado es, pues, una organización no una supranación o un supraestado.

- Dado que las competencias que se le atribuyen afecta, a diferencia de la generalidad de las organizaciones, a funciones esenciales de los Estados, es preciso que con carácter previo éstos hayan adecuado sus Constituciones internas para que se posibilite tal transferencia de competencias. $Y$ tal hecho hace que estas organizaciones sean de un tipo nuevo, no meras organizaciones de cooperación.

- La atribución de competencias es, por consiguiente, un acto voluntario de los Estados miembros, de manera que es necesario prever en qué ámbitos los Estados están dispuestos a renunciar voluntariamente al ejercicio de una parte de su soberanía en beneficio de unas instituciones a las que dotan de la facultad de elaborar unas voluntades propias y autónomas.

- Desde el momento en que se concluyen los Tratados constitutivos, los Estados quedan internacionalmente obligados (art.26 de la Convención de Viena sobre el Derecho de los tratados entre Estados de 1969) y no podrán invocar disposiciones de sus Constituciones para eludir el cumplimiento de lo dispuesto en aquellos tratados (arts. 27 en relación con el 46 de la citada Convención).

- Las organizaciones resultantes no disfrutan de una competencia general, sino que se le determinan los ámbitos en los que puede actuar. Estas competencias pueden también deducirse del sistema de los Tratados.

- La integración respeta la identidad de los Estados miembros y se basa en el diálogo permanente entre los intereses nacionales y el interés comunitario y en el que se respeta las diversidades nacionales.

- Los Estados están presentes a lo largo de todo el proceso, de manera que las renuncias que van haciendo a sus propias facultades es previsible y controlable. Ellos son, en suma, quienes definen el proceso y quienes marcan su ritmo.

- Para que avance este proceso es necesario que se vayan produciendo delegaciones del ejercicio de la soberanía por parte de los Estados miembros, lo que significa abandonar el dogma de la soberanía absoluta y reconocer que el ejercicio de la soberanía, cuya titularidad ostentan los Estados y que radica, en definitiva, en el pueblo, puede ser cedida si con ello se facilita el logro de una serie de objetivos colectivos y superiores que se estiman como prioritarios y beneficios para el conjunto de la población de estos Estados. Ello puede exigir que a cada avance significativo que se produzca, los Estados hayan respondido, previamente, con una revisión constitucional que lo permita.

En resumen, integración y supranacionalidad en sentido de supraestatalidad, son expresiones cercanas pero no sinónimas. Puesto que la integración no exige la renuncia por parte de los Estados miembros a su soberanía, solamente precisa que éstos, en virtud de dicha soberanía, cedan voluntariamente el ejercicio de la misma a la organización de que se trate. Supranacionalidad en tanto supraestatalidad significaría, en cambio, que estamos más allá de una mera cesión del ejercicio de la soberanía y que aparecen nuevos entes internacionales por encima de los Estados dotados de soberanía. Por mi parte, yo pienso que tal cosa no se produce por lo que respecta a la Unión Europea, por lo que prefiero hablar, hoy por hoy, de un proceso de integración, sustentado en la primacía del Derecho comunitario y en la eficacia directa de sus normas. Aunque no descarto que una vez agotada la técnica integradora sea necesario pasar a otra fase nueva que precisaría de la elaboración de una verdadera Constitución europea y, en este sentido, cincuenta años de aplicación de la mencionada técnica parecen mostrar que ésta ya no es suficiente para hacer avanzar el proceso de construcción europeo, lo que explica la emergencia de nuevas -tal vez no tan nuevas- manifestaciones a favor de modelos federales para Europa. 
Al comenzar a mostrar señales de fatiga el proceso de integración, se multiplican las reflexiones en torno a la federalización en Europa. Este nuevo proceso se sustentaría en un Tratado-Constitución que, por ejemplo, en el pensamiento del Ministro de Asuntos Exteriores alemán Joschka Fischer, debería sustentarse en los Estados nación sin reemplazarlos. Tal difícil ecuación se sustentaría sobre el reparto de soberanía entre Europa y los Estados nación a través de la aplicación del principio de subsidiariedad, al que se le daría rango constitucional. Según estas ideas, las instituciones deberían representar tanto a los Estados nación como a los ciudadanos europeos, estableciendo, por ejemplo, en el Parlamento Europeo, dos cámaras, una formada por diputados elegidos por los ciudadanos y otra por senadores extraídos de los Estados miembros, o un presidente de la Comisión elegido mediante sufragio directo por los ciudadanos, etc.

Estos planteamientos, no muy alejados de otros efectuados por personalidades europeas como H. Schimdt, V. Giscard o J. Delors, retoman la idea de una Federación de Estados nación sustentada en un núcleo reducido de países. Puesto que lógicamente habrá países europeos que no quieran o no estén en condiciones de participar completamente en una aventura jurídico-política de tal envergadura. De este modo se apunta hacía la utilización del mecanismo, introducido por el Tratado de Maastricht de 1992, consistente en la cooperación reforzada, de manera que un grupo más o menos pequeño de países la llevarían a cabo y en su marco elaboraría un nuevo Tratado que a su vez constituiría el núcleo de la futura Constitución de la Federación, en la que se preverían instituciones propias tales como Gobierno con un Presidente directamente elegido por los ciudadanos y un Parlamento bicameral.

Algunas de las cuestiones que son objeto de debate en los trabajos de la Convención y que deberán quedar resueltas para la reforma de los Tratados constitutivos, tales como el lugar que debe ocupar la Carta de Derechos Fundamentales de la Unión Europea o la delimitación de competencias entre la UE y los Estados miembros, plantean directamente el problema del agotamiento del modelo comunitario pensado inicialmente para una pequeña comunidad de Estados con objetivos esencialmente económicos, y suscita la conveniencia de dar el salto hacia un modelo diferente fruto de una "Constitución" europea que rija en una UE económica, política y social.

Una UE que, en mi opinión, seguirá siendo una organización internacional, dotada de competencias de atribución, definida por una Constitución-Tratado en aplicación de los principios de subsidiariedad y proporcionalidad y generalmente compartidas entre los Estados miembros y las instituciones comunitarias.

Una Constitución que en la línea de lo adelantado por el Informe Lamassoure del Parlamento Europeo de 24 de abril de 2002 debería ser dirigida a todos los ciudadanos y concebida como un pacto de refundación que fusionaría los diferentes Tratados en un solo texto y afectaría a una sola entidad, la Unión, dotada de personalidad jurídica única y completa, lo que significaría comunitarizar los pilares segundo y tercero de la UE y garantizar su control parlamentario y jurisdiccional.
Este Tratado constitucional sustituiría al modelo actual de UE basado en cuatro Tratados básicos, donde las políticas son realizadas mediante procedimientos diferentes según sus ámbitos de actividad, y de la que además algunos Estados miembros se autoexcluyen y no participan en todas ellas. El Tratado constitucional, al fusionar los Tratados permitiría también simplificar y racionalizar la arquitectura institucional comunitaria, clarificando, también la organización de los poderes públicos europeos y cuyo valor, tal y como se dice en la Comunicación de la Comisión sobre un Proyecto de la Unión Europea [COM (2002) 247 final, 22.5.2002], sea entendido por los ciudadanos europeos como el que tiene una constitución para un Estado miembro.

Esta Constitución, más clara y legible que los textos actuales, consagraría el principio de separación, equilibrio y cooperación entre los poderes legislativos, ejecutivos y judiciales de la Unión, incluiría un marco relativo a las competencias, distinguiendo entre las competencias propias atribuidas a la Unión, las competencias de principio de los Estados y las competencias compartidas y también integraría la Carta de los Derechos fundamentales de la UE en su cuerpo jurídico, al tiempo que simplificaría la adopción y la aplicación de las decisiones de la Unión.

Este texto no podrá ser sólo el resultado de un acto diplomático internacional (un nuevo tratado entre los Estados miembros de la UE) sino que deberá ser el resultado de un proceso democrático en el que participe el Parlamento europeo, los Parlamentos nacionales de los Estados miembros y de los Estados candidatos, los Parlamentos regionales de aquellas regiones con poderes legislativos y la propia opinión pública.

La duda está en saber si la presente Convención da cobijo a tal proceso democrático y si su resultado será respetado en la Conferencia intergubernamental de la que saldrá el nuevo Tratado-Constitución. En este sentido y frente a la idea de Derecho interno de Constitución me parece preferible utilizar la expresión de Tratado-Constitución o Tratado constitucional, puesto que el futuro texto jurídico seguirá siendo un tratado internacional, de corte constitucional, en la línea del art. 5 del Convenio de Viena sobre el Derecho de los Tratados de 1986. Esto es, un tratado entre sujetos soberanos, los Estados, que dan nacimiento a otro sujeto internacional: la nueva UE. Distintos niveles de poder coexistirán en el espacio jurídico definido por este Tratado-Constitución, habrá nuevos repartos de competencias entre los mismos, correspondiendo, en último término, al Tribunal de Justicia garantizar el respeto del derecho en el ejercicio de dichas competencias, lo que supone reforzar su función de Tribunal Constitucional en la nueva etapa de la integración europea que, a estas alturas, significa ya algo más que una mera integración progresiva de diversos países de Europa. 